\title{
Assistência e educação de desvalidas no século XIX: o Asilo de São João de Lisboa
}

\section{(Care and education of vulnerable girls in the nineteenth century: St John's Asylum, Lisbon)}

\author{
Nuno MARTINS FERREIRA \\ Escola Superior de Educação - Instituto Politécnico de Lisboa
}

RESUMO: 0 Asilo de São João foi fundado em Lisboa, em 1862, por iniciativa de um grupo de maçons, de modo a garantir assistência e educação a jovens raparigas, até então à guarda da congregação religiosa das Irmãs da Caridade. Este estudo, que parte da consulta de fontes documentais, nomeadamente de informações contidas em relatórios e contas da Instituição, tem por objetivo dar a conhecer 0 contexto em que 0 Asilo foi instalado e quais os principais aspetos que caracterizaram o seu funcionamento, com notas que convidam a um olhar sobre 0 seu quotidiano, ao longo do século XIX. 0 seu aparecimento navegou entre 0 debate acerca do papel que as congregações religiosas tinham na educação dos mais desfavorecidos e o espírito filantrópico de uma sociedade que vivia sob a crença no progresso material e social. Da investigação realizada, salienta-se a preocupação de dotar as jovens asiladas de competências para se integrarem na sociedade, bem como as dificuldades sentidas pelas direções em manter de pé esta obra de carácter social.

PALAVRAS-CHAVE: Asilo de São João de Lisboa; Maçonaria; Questão das Irmãs da Caridade; História da Educação; Século XIX.

ABSTRACT: St John's Asylum was founded by a group of Freemasons in Lisbon in 1862 for the care and education of vulnerable young women following their release from homes run by the Sisters of Charity. The aim of this study is to examine the context in which the asylum was established, the activities that took place there, and the day-to-day running of the institution as a whole, based on an analysis of the asylum's reports and accounts. The creation of St John's Asylum reflects the questioning at the time of the role of religious orders in the education of society's most disadvantaged and the belief in material and social progress that permeated the philanthropic spirit of the age. The study highlights the attempt to provide young women with the skills they needed to integrate into society, and the problems faced by the asylum's directors to keep the institution running.

KEY WORDS: St John's Asylum; Freemasons; role of religious orders; history of education; nineteenth century. 


\section{Introdução}

No seu livro Maria da Fonte, Camilo Castelo-Branco colocou uma pergunta a que respondeu de pronto: "Sabe como procedeu José Estêvão com as crianças subtraídas às irmãs da caridade expulsas? Fundou o Asilo de S. João a expensas da maçonaria $\mathrm{e}$ aí foram recebidas as crianças de todos os estabelecimentos fechados à influência da caridade francesa". ${ }^{1}$

Tanto a pergunta como a resposta marcam o ponto de partida deste trabalho: a criação do Asilo de São João de Lisboa (ASJ), em 1862, cuja história é ainda pouco conhecida, na sequência de um debate ideológico e político em torno da assistência e da educação Oitocentistas, que teve na batizada Questão das Irmãs da Caridade o seu epicentro.

Para além de ser referenciado em obras gerais dedicadas à História da Maçonaria, são poucos os estudos dedicados ao ASJ. Do que conseguimos apurar, existem duas referências. A primeira é da autoria do, então, diretor-secretário da instituição, Ventura Reimão, que escreveu uma pequena monografia para apresentá-la no X Congresso Internacional de Proteção à Infância, que ocorreu em 1931, em Lisboa. A segunda referência é um trabalho policopiado, datado de 1992, da autoria de Manuel Roque de Azevedo, intitulado História do Internato de S. João de Lisboa. Roque de Azevedo, que integrou as direções do então Internato ${ }^{2}$ entre os anos de 1975 e de 1987, escreveu um texto que contempla aspetos da vida da instituição ao longo de 125 anos de existência (18621987). A principal fonte utilizada neste trabalho dá pelo nome de Associação Protectora do Asylo de S. João para a infância desvalida: Relatório e contas, que inclui os anos económicos de 1867/1868 a 1888/1889. Aí encontramos informação contabilística, mas também dados referentes a movimentações de admissão ou saída de alunas, situações clínicas, mapas diversos com discriminação de receitas e de despesas, e com notas de exames das alunas internas e externas. Para além disso, cada exercício começa por fazer um ponto da situação com o que de mais relevante aconteceu nesse ano.

0 texto aqui apresentado encontra-se dividido em três partes: na primeira é feita a contextualização em torno da Questão das Irmãs da Caridade, que levaria à criação do asilo; na segunda aborda-se a iniciativa de maçons para criar uma instituição asilar e os principais aspetos regulamentares e funcionais da mesma; e, na terceira, procura-se ilustrar a vida do asilo, durante as primeiras duas décadas, com destaque para as dificuldades sentidas para mantê-lo em atividade.

\footnotetext{
${ }^{1}$ Camilo Castelo-Branco, Maria da Fonte (Porto: Livraria Chardron, 1900), 219.

${ }^{2}$ Por despacho ministerial de 20 de janeiro de 1972, o Asilo passou a ser designado por Internato de São João. Durante 150 anos, a instituição suportou a infância feminina e, a partir de 2012, passou a apoiar estudantes do ensino superior com carência de alojamento.
} 


\section{Nos meandros da fundação do Asilo (1862)}

As primeiras décadas de Oitocentos trouxeram a aspiração de uma nova sociedade. 0 papel da Igreja Católica seria posto em causa, por ser uma marca identitária de uma pirâmide social mais imóvel e menos permeável à entrada de novas ideias. A luta entre mundividências trazida à luz pela Revolução de 1820 não era, pelo menos nas primeiras décadas do século, uma afronta à existência do Catolicismo — o Homem liberal era, na sua maioria, católico - mas sim ao poder que o clero mantinha junto das estruturas sociais. Como tal, o discurso liberal não seria anticatólico, mas sim anticongreganista, pelo peso que as congregações religiosas detinham, nomeadamente na educação. Esta dimensão seria amplamente discutida em sede parlamentar, no contexto da presença das Irmãs da Caridade. ${ }^{3}$

A Questão das Irmãs da Caridade viria acirrar os ânimos dos herdeiros de um anticlericalismo liberal, numa sociedade que caminharia, no último quartel do século XIX, para uma forte oposição ideológica assente em valores republicanos e socialistas. ${ }^{4}$ Até à implantação da República, em 1910, as vozes defensoras do antijesuitismo, do anticongregacionismo e do antiultramontanismo passariam de uma fase defensiva e de crítica apontada à ignorância e ao conservadorismo tomado por anacrónico, a uma fase pautada por acérrimas campanhas anticatólicas. ${ }^{5}$

A partir dos meados do século XIX, deu-se início ao período da regeneração industrial do País, que teve 0 suporte do crescimento das principais cidades, sobretudo no litoral. A sociedade conheceria evidentes mutações, com a crescente urbanização dos principais polos de indústria, ao mesmo tempo que a influência da Igreja católica ia perdendo a sua força, em termos de construção de uma mundividência arreigada aos valores tradicionais. 0 desenraizamento da população, que abandonava a sua terra natal para procurar melhores condições de vida em cidades mais ou menos próximas, seria, sobretudo nas últimas décadas de 0itocentos, um terreno fértil para a propaganda dos ideais republicanos e laicos. 0 avanço tecnológico e a imposição da ciência como motor de desenvolvimento material e social levariam a uma recuperação das ideias racionalistas do século XVIII e à tendência para a laicização da sociedade, que responderia melhor a um pensamento/ ação libertos das amarras do Catolicismo. ${ }^{6}$

Em 1857 chegou a Portugal um grupo de Irmãs da Caridade francesas para auxiliar a debelar as epidemias do cólera-morbo e da febre-amarela. Esta ajuda seria autorizada pelo Governo, incapaz de resolver os problemas relacionados com a assistência pública. ${ }^{7}$

\footnotetext{
${ }^{3}$ Vítor Neto, 0 Estado, a Igreja e a Sociedade em Portugal (1832-1911) (Lisboa: Imprensa Nacional-Casa da Moeda, 1998).

${ }^{4}$ José Carvalho, "Anticlericalismo/anticatolicismo e clericalismo/catolicismo em Portugal nas vésperas da I República (1881-1910) - breve panorâmica histórico", Revista Lusófona de Ciência das Religiões, 20 (2017): 283-311.

${ }^{5}$ Fernando Catroga, "0 livre-pensamento contra a Igreja. A evolução do anticlericalismo em Portugal (séculos XIX-XX)", Revista de História das Ideias, vol. 22 (2001): 255-354.

${ }^{6}$ Fernando Catroga, "0 livre-pensamento contra a Igreja".

7 "A extinção destas [ordens religiosas] ou, pelo menos, a sua redução gradual, a partir de 1834 levou a uma diminuição, quer dos organismos dispensadores de cuidados quer da mão-de-obra operativa, sentidos
} 
Naturalmente que a oposição anticlerical não viu com bons olhos a entrada de religiosas, sobretudo num contexto de impotência governamental em assegurar essa assistência pública que, tendo em conta o trabalho exercido na comunidade pelas irmãs francesas, se travestia de caridade cristã ${ }^{8}$

Num manifesto da Associação Popular Promotora da Educação do Sexo Feminino, dirigido ao Partido Liberal Português, em 1858, Alexandre Herculano faria uma crítica contundente aos pretensos liberais que pouco ou nada se preocuparam com o futuro das novas gerações, dizendo que a educação não era coisa de partidos.

A Associação Popular Promotora tinha sido criada ${ }^{9}$, com envolvimento direto de Alexandre Herculano, para evitar que a educação popular fosse transviada para a esfera das congregações religiosas "não só estrangeiras, mas também regidas por princípios opostos às instituições do estado". ${ }^{10}$

A herança oferecida pela introdução do Liberalismo não podia ser desperdiçada, sobretudo por todos aqueles que "sonham na restauração do passado"11. Ainda para mais, no seu entendimento, não fazia sentido introduzir no País "[...] mestras estrangeiras, pertencentes a uma corporação do sexo feminino, que, conservando a sua organização atual, é incompatível com as leis e instituições do país". ${ }^{12}$ Perguntava se não haveria entre um milhão de portuguesas algumas mulheres capazes de se

encarregar da santa e nobre missão de serem mães adotivas dos órfãos tutelados pela comiseração pública? A ciência da educação inspira - a Deus por metade ao coração da mulher, porque 0 destino providencial desta é a maternidade: a outra metade dão-Iha as tradiçõos domésticas, as recordações dos primeiros anos, 0 ensino dos livros e dos mestres e a observação da sociedade..$^{13}$

A posição da Associação Popular Promotora foi um exemplo da gramática acusatória em torno da ação educativa das congregações religiosas. A 11 de março de 1862 era apresentada uma proposta de lei na Câmara dos Deputados que proibia a

principalmente em períodos de calamidade e da consequente intensificação de atividades", A. H. de Oliveira Marques, "A conjuntura”, em Portugal e a Regeneração (1851-1900) [Nova História de Portugal, vol. X], dirigido por Fernando de Sousa e A. H. de Oliveira Marques (Lisboa: Editorial Presença, 2004), 473.

${ }^{8}$ Vítor Sérgio Quaresma, A Regeneração. Economia e sociedade (Lisboa: Dom Quixote, 1998). Desde 1819 que as Irmãs da Caridade se encontravam sediadas em diversos locais na cidade de Lisboa. A abolição das Ordens Religiosas, em 1834, fez com que as ordens masculinas fossem desmanteladas e as femininas ficassem proibidas de receber noviças, o que, na prática, levaria à sua extinção por falta de renovação de religiosas. Contudo, as Irmãs da Caridade escapariam a esta proibição em virtude dos seus votos temporários e do caráter humanitário da sua missão.

${ }^{9}$ A Associação tinha por objetivo promover a instalação de escolas primárias para crianças e a de uma escola de formação de mestras, futuras professoras para aquelas escolas. Os seus estatutos foram aprovados a 6 de abril de 1859. Ver Collecção Official da Legislação Portugueza, ano de 1859 (Lisboa: Imprensa Nacional, 1960), 95-98.

${ }^{10}$ Alexandre Herculano, Ao Partido Liberal Portuguez, a Associação Popular Promotora da Educação do Sexo Feminino (Lisboa: Imprensa União Typographica, 1858), 3.

${ }^{11}$ Alexandre Herculano, Ao Partido Liberal Portuguez, 4.

${ }^{12}$ Alexandre Herculano, Ao Partido Liberal Portuguez, 5.

${ }^{13}$ Alexandre Herculano, Ao Partido Liberal Portuguez, 10. 
existência de comunidades ou congregações religiosas em Portugal que tivessem sido introduzidas ou modificadas após a publicação dos decretos de 9 de agosto de 1833, de 28 de maio e de 28 de julho de 1834. Essa proposta seria apreciada por uma comissão especial, composta por nomes maioritariamente regeneradores e presidida por Fontes Pereira de Melo.

0 parecer da comissão chegaria a 26 de abril de 1862, defendendo a interdição de acesso e de atividade de congregações religiosas estrangeiras em estabelecimentos nacionais de instrução públicos, fossem eles mantidos pelo Estado central, pelos distritos ou estivessem sob a alçada dos municípios. ${ }^{14}$ Para além destas interdições, a comissão instava o governo a organizar o ensino de crianças "nos estabelecimentos de beneficência, tanto públicos como particulares, regulando tudo 0 que respeitar à sua administração, regime e direção moral" ${ }^{15}$

A instrução, outrora nas mãos da Igreja Católica, devia ser uma prioridade do Estado. Como tal, defendia aquela comissão uma visão utilitarista da educação, ao invés de uma escola formadora de praticantes religiosos. ${ }^{16}$ Ainda que se demarcassem de uma educação católica, que tinha do seu lado o peso da tradição na história portuguesa, entendiam, todavia, a importância da religião para a formação dos cidadãos. A moralidade, a dignidade, 0 respeito pelos direitos e uma liberdade responsável eram fatores que implicavam um contacto com o Evangelho, mas numa atitude de compreender e não de decorar cegamente a mensagem de Cristo.

Como tal, a discussão em torno do papel das Irmãs de Caridade, que mais não era do que a personificação de um debate entre a influência da Igreja Católica num Portugal liberal e a vontade de laicizar a educação nacional ${ }^{17}$, ganhou natural amplitude nos periódicos ${ }^{18}$ e nas Cortes.

\footnotetext{
${ }^{14}$ Parecer da maioria da comissão especial da Câmara dos Deputados sobre a proposta do Governo acerca das Congregações Religiosas e do ensino, apresentado na sessão de 26 de abril de 1862 (Lisboa: Typographia da Sociedade Typographica Franco-Portugueza, 1862).

${ }^{15}$ Parecer da maioria da comissão especial da Câmara dos Deputados, 3.

16 "A educação geral não é destinada a preparar indivíduos para as contemplações da vida ascética, nem a cultivar espíritos para disputas escolásticas e metafísicas. As escolas devem ser um viveiro abundante de cidadãos úteis, de homens honestos e boas mães de família", Parecer da maioria da comissão especial da Câmara dos Deputados, 49.

${ }^{17}$ De acordo com os seus detratores, aquelas religiosas "seriam fanáticas e prosélitas, constituindo a ala e arma feminina dos Lazaristas e, por via destes, do jesuitismo internacional. Dariam preferência aos doentes ricos sobre os pobres. Dedicavam-se ao ensino sem estarem, para isso, habilitadas", Marques, «A conjuntura», 473. 0 exemplo do que se passava em França influenciou o caso português, sobretudo porque aquele sistema escolar foi construído com base numa vontade da sua secularização, 0 que traria evidentes focos de tensão entre a Igreja Católica e 0 Estado gaulês. Em plena Terceira República francesa, as leis escolares de Jules Ferry teriam um impacto importante na distinção das esferas religiosa e laica no que à educação em França dizia respeito, sobretudo as leis de 1882 e de 1886, por terem imposto a laicidade na escola. Valentine Zuber, "A laicidade republicana em França ou os paradoxos de um processo histórico de laicização (séculos XVIII-XXI)", Ler História, 59 (2010): 161-180.

${ }^{18}$ Foi o caso dos jornais 0 Portuguez, O Futuro, Revolução de Setembro, 0 Parlamento ou Jornal do Comércio.
} 
José Estêvão Coelho de Magalhães, então Grão-Mestre da Confederação Maçónica Portuguesa, foi uma das figuras mais proeminentes da defesa da extinção da Congregação das Irmãs da Caridade. No primeiro ${ }^{19}$ de dois discursos que proferiu em sede parlamentar, marcaria claramente a sua posição face à polémica, ao assumir que era totalmente contra a manutenção da congregação religiosa em Portugal, colocando a tónica da sua intervenção na instrução, mas que deveria estar apartada da prática caritativa. No segundo discurso ${ }^{20}$, voltaria a abordar a questão educativa, acusando os defensores da Congregação de verem nas Irmãs as únicas guardiãs do conhecimento e da sua transmissão. Não sendo adepto de religiões da maioria, porque entendia que a crença religiosa era da esfera privada e da consciência de cada um, opunha-se veementemente a um ensino dependente dos ditames e práticas religiosos de irmãs francesas, quando muito caberia à Igreja portuguesa assegurar a formação.

Importa dizer que esta questão não foi assumida pelas maçonarias ${ }^{21}$ como uma causa comum. A historiografia mais recente faz uma releitura dos acontecimentos e, não alinhando com a posição de Oliveira Marques ${ }^{22}$, descentra o peso da organização maçónica para 0 plano individual dos seus membros. ${ }^{23}$ Com isto queremos dizer que 0 debate que se levantou teve nas suas fileiras posições individuais de maçons liberais de esquerda e não foi assumido por organizações maçónicas, no caso a Confederação Maçónica, que, neste período temporal se encontrava a braços, aliás, com problemas internos. ${ }^{24}$

Esta questão religiosa terminaria em 1862 com o repatriamento das Irmãs francesas. Assim se punha fim a uma tensão que extravasou as posições individuais de parlamentares e intelectuais, isto porque o que estava em causa era o modelo de Estado, incapaz de substituir em número e qualidade o papel assistencial e educativo que tinha sido monopólio da Igreja desde há séculos. A intervenção de maçons teve influência neste

\footnotetext{
${ }^{19}$ José Estêvão, Discursos Parlamentares (Aveiro: Câmara Municipal de Aveiro, 1997). Discurso de 9 de julho de 1861.

${ }^{20}$ José Estêvão, Discursos Parlamentares, discurso de 10 de julho de 1861.

${ }^{21}$ Seguimos a análise de Fernando Marques da Costa, que defende ser mais correta, à luz dos acontecimentos, a utilização do termo 'maçonarias' ao invés de 'Maçonaria' quando nos referimos à evolução dos seus ideais ao longo de boa parte do século em questão. Fernando Marques da Costa, $A$ Maçonaria entre a forca e 0 cacete, entre o mito e a realidade. 1807-1834 (Lisboa: Campo da Comunicação, 2018), 39-40. Só a partir da constituição do Grande Oriente Lusitano Unido, em 1869, é que podemos assistir a um centralismo agregador do ponto de vista administrativo, organizacional e ritualístico da Maçonaria em Portugal.

${ }^{22}$ Este historiador considerou que a oposição à permanência daquela congregação em Portugal foi um combate assumido pela Maçonaria nacional na sua forma institucional. A. H. de Oliveira Marques, História da Maçonaria em Portugal. Política e Maçonaria, 1820-1869 (1. a parte) (Lisboa: Editorial Presença, 1996).

${ }^{23}$ Fernando Marques da Costa, As mulheres na Maçonaria. Portugal: 1864-1950 (Lisboa: Âncora Editora; Campo da Comunicação, 2016); António Ventura, Uma história da Maçonaria em Portugal. 1727-1986 (Lisboa: Temas e Debates; Círculo de Leitores, 2020).

${ }^{24} \mathrm{~A}$ decadência da Confederação Maçónica, criada em 1849, agudizou-se na disputa pela liderança, na sequência da morte do então Grão-Mestre José Estêvão Coelho de Magalhães, em 1862. A contenda foi entre 0 2..$^{\circ}$ Duque de Loulé, que fora Grão-Mestre em 1852, depois de 1853 a 1856 e de novo de 1859 a 1860, e 0 Ministro da Fazenda, Joaquim Tomás Lobo de Ávila, que exerceria funções entre 1863 e 1864.
} 
desfecho, que rapidamente encontrariam uma solução para a desproteção em que caíram algumas jovens sem 0 abrigo daquela congregação religiosa.

\section{A criação do Asilo}

No século XIX, o Estado, sobretudo a partir da nova ordem liberal surgida em 1820, seria mais interventivo na gestão dos problemas sociais, à medida que se delimitavam as esferas de influência do poder laico e do poder religioso. A pobreza ou 0 apoio aos mais desfavorecidos, ou desvalidos desta vida, criou um "dever público na assistência, com a perspectiva de beneficência ${ }^{25}$ e não como prática de caridade. A beneficência procedia a filantropia, 0 amor aos homens, e não a caridade, 0 amor a Deus" ${ }^{26}$

Na sua monumental obra, José Silvestre Ribeiro incluiu as casas de asilo da infância desvalida no conjunto de instituições de ensino existentes em Portugal. A justificação para tal foi dada nos seguintes moldes:

Se estes recomendáveis estabelecimentos têm essencialmente 0 carácter de caridade e beneficência, é certo, por outro lado, que procuram eles às criancinhas das classes menos abastadas 0 ensino elementar e a educação, e entram, debaixo deste ponto de vista, no plano do nosso trabalho. ${ }^{27}$

A assistência à infância desvalida, como eram chamadas as crianças pobres e carentes de apoio social, era uma realidade no início do século XIX. Desde o século XVIII que começariam a surgir diferentes modelos pedagógicos de educação/instrução em instituições já existentes, a par do aparecimento, sobretudo na centúria seguinte, de estabelecimentos criados com o propósito de acolher, proteger, assistir e reeducar menores de idade. Esses novos espaços, nos quais se integra 0 asilo, "estiveram ligados, na sua origem e génese evolutiva, a movimentos, associações e sociedades beneméritas, religiosas, filantrópicas e comunitárias". ${ }^{28}$

Consoante as situações familiares, crianças órfãs ingressavam em instituições religiosas como colégios, seminários ou recolhimentos. Em 1833 foram criados os Asilos de Infância Desvalida, inspirados nas francesas Salles d'Asile, na sequência do aumento de órfãos menores de famílias vítimas das invasões napoleónicas. Se é certo que ainda

\footnotetext{
25 "A palavra teve sucesso no discurso liberal (assim como a variante "benemerência"), assumindo uma acepção laica. Por vezes beneficência e caridade são confundidas, mas na realidade são conceitos totalmente distintos. Para além do facto de ser a caridade um sentimento e a beneficência um acto, esta última, no sentido vulgarizado do termo (não no dos teólogos), é humanista, gerada pela filantropia". Maria Antónia Lopes, Protecção social em Portugal na Idade Moderna. Guia de estudo e de investigação (Coimbra: Imprensa da Universidade de Coimbra, 2010), 31.

${ }^{26}$ Ricardo Cordeiro, "Filantropia. As Cozinhas Económicas de Lisboa (1893-1911)" (Dissertação de Mestrado, ISCTE - Instituto Universitário de Lisboa, 2012), 19.

${ }^{27}$ José Silvestre Ribeiro, Historia dos estabelecimentos scientificos, litterarios e artisticos de Portugal nos successivos reinados da Monarchia (Lisboa: Academia Real das Ciências, 1876, t. VI), 236.

${ }^{28}$ Ernesto Candeias Martins, As infâncias na história social da educação. Fronteiras e interceções sóciohistóricas (Lisboa: Editorial Cáritas, 2018), 192.
} 
hoje não existe um estudo aprofundado das motivações e da complexidade do contexto político, económico, social, médico, demográfico ou cultural que estiveram na origem dos asilos, sabe-se que a filantropia ${ }^{29}$ foi determinante para a sua consolidação em Portugal: "0 discurso filantrópico animou, desde o começo, as iniciativas deste movimento que, em Portugal, teve uma orientação mais psicopedagógica. Ou seja, os asilos conjugavam na sua missão as funções de proteção social/assistencial e o seu projeto educativo/ formativo". ${ }^{30}$

A fundação do ASJ foi um dos exemplos da atividade prática de que falou Marques ${ }^{31}$ levada a cabo por maçons, ainda que numa data precoce ao que seria a ação filantrópica ou de beneficência de lojas maçónicas, ou de maçons, nas décadas seguintes, de que foi exemplo a criação, em 1890, do Asilo de São João do Porto, para rapazes, fruto da iniciativa de um conjunto de maçons pertencentes a quatro Lojas daquela cidade Independência Lusitana, Independência, Liberdade, Honra e Dever. Ao contrário do que sucederia em Lisboa, no Porto este Asilo não surgiria na sequência de uma questão religiosa mas antes como resposta a problemas sociais e de saúde pública que fragilizariam a condição infantil. ${ }^{32}$

No caso de Lisboa, Fernando Catroga associou diretamente a expulsão da Congregação de Portugal com a fundação do Asilo: "E, para dar cumprimento à vocação filantrópica da maçonaria, José Estêvão fundou o Asilo de S. João, organização que ganhou raízes, transformando-se na obra mais duradoura da filantropia maçónica". ${ }^{33}$ Em apenas dois meses, junho e julho de 1862 respetivamente, as Irmãs da Caridade foram expulsas do território nacional e ASJ foi fundado.

No dia 1 de junho, uma comissão, organizada por António de Sousa Menezes e por José Maria Lobo de Ávila dirigiu um ofício ao ministro do Reino, Anselmo José Braamcamp, com o objetivo de oferecer a sua contribuição perante a saída das congregadas. A resposta vinda do Paço da Ajuda, chegaria no dia seguinte, assinada pela pena do mi-

\footnotetext{
${ }^{29}$ A filantropia ganharia expressão tardia no século XIX, apesar de ter aparecido em França, no ano de 1772, na escrita do teólogo francês, de ideias liberais, François Fénelon. Traduzia-se por um amor ao próximo e por atos de generosidade para com os demais. A moral católica rejeitaria a ideia de filantropia, isto porque estes atos eram entendidos como desligados da ideia de Deus ou das suas obras. Lopes, Protecção social em Portugal na Idade Moderna.

${ }^{30}$ Martins, As infâncias na história social da educação, 192.

${ }^{31}$ A. H. Oliveira Marques, A Maçonaria em Portugal (Lisboa: Gradiva, 1998).

32 " [...] 0 encerramento de numerosas oficinas, sobretudo ligadas à tecelagem do algodão e à chapelaria, os despedimentos de grande número de operários, a redução dos salários de muitos outros, foram fatores que contribuíram amplamente para agravar as difíceis condições de vida e de habitação de largos sectores da população mais carenciada, publicitadas na sua duríssima realidade pelas consequências da peste bubónica de 1889 e que afetaram sobretudo os seus membros mais frágeis, entre os quais se encontravam as crianças", Maria José Moutinho Santos, Memórias do Internato de S. João do Porto (1890-1974) (Porto: Associação Protetora do ISJ, 2012), 35.

${ }^{33}$ Fernando Catroga, "As maçonarias liberais e a política", em História de Portugal, dirigido por José Mattoso (Lisboa: Círculo de Leitores, 1993, vol. 5), 209.
} 
nistro do Reino. 0 governo aceitava os préstimos daquele grupo de cidadãos signatários e esperava que as visadas com esta atitude caritativa, as crianças, fossem beneficiadas.

É aqui que se enquadra a ação de um conjunto de maçons ${ }^{34}$, que fundariam, por sua iniciativa, a 2 de julho de 1862, o ASJ, cujo intuito era 0 de acolher um número de 20 raparigas que se achavam recolhidas no Asilo dos Cardais de Jesus. ${ }^{35}$

0 primeiro regulamento interno data de dezembro de 1864 , tendo sido publicado no ano seguinte.$^{36}$ Nele se incluem diversos capítulos e respetivos artigos, que nos dão, hoje, uma ideia da forma como 0 Asilo se organizava em termos do seu quotidiano. ${ }^{37}$

As raparigas entravam no Asilo com idades entre os cinco e sete anos e saíam aos 15 anos. Para a admissão, as candidatas deveriam apresentar os seguintes documentos: certidão de idade; certidão de óbito do pai, da mãe ou de ambos; certidão de vacina e prova de que não padeciam de doenças contagiosas; e atestado de pobreza, passado pelas autoridades civil e eclesiástica. Tinham prioridade de entrada as filhas de sócios da Associação Protetora do Asilo de São João (APASJ) ${ }^{38}$, seguindo-se as órfãs de pai e mãe; órfãs de mãe ou de pai, estando o progenitor vivo impossibilitado de assegurar a subsistência.

0 Regulamento faz transparecer uma implícita preocupação com 0 bem-estar das raparigas, mas também com o cumprimento de regras, necessárias ao normal funcionamento da instituição. Por exemplo, competia aos três vogais "fazer visitas inesperadas para descobrir qualquer irregularidade, vigiando especialmente se a comida é administrada às alumnas por modo conveniente, e em observância das regras estabelecidas". ${ }^{39}$ Existiam igualmente quatro inspetores a quem cabia a fiscalização do normal funcionamento da instituição e zelar pelo bom cumprimento das disposições do regulamento "mediante visitas e exames necessários". ${ }^{40}$

\footnotetext{
${ }^{34}$ Os membros da Confederação Maçónica Portuguesa que estiveram na origem do Asilo foram os seguintes: José Estêvão Coelho de Magalhães, José Isidoro Viana, António de Sousa Menezes, Francisco Maria Eneia, José Maria Lobo de Ávila, Gilberto António Rola, Inácio Januário da Silva Avelino e José Joaquim de Abreu Viana.

${ }^{35}$ Marques, "A Conjuntura", 467-518.

${ }^{36} 0$ primeiro regulamento interno, de 31 de dezembro de 1864 , foi elaborado pela direção e aprovado pela APASJ na sua sessão de 5 de janeiro de 1865. Ventura Reimão, 0 Asilo de S. João. Monografia a apresentar ao $X$ Congresso Internacional de Protecção à Infância, Lisboa (Caxias: Tipografia do Reformatório Central de Lisboa Padre António de Oliveira, 1931); Os primeiros estatutos conhecidos foram aprovados pela APASJ a 29 de abril de 1867 e pela carta de Lei de D. Fernando, de 9 de julho do mesmo ano. Manuel Roque de Azevedo, História do Internato de S. João de Lisboa (ex-Asilo de S. João) - 1862-1987. 125 anos de solidariedade social [texto policopiado, 1992].

${ }^{37}$ Regulamento Interno do Asylo De S. João approvado e mandado observar pela Associação Protectora do mesmo Asylo, (Lisboa: Typographia Portugueza, 1865).

38 "Os sócios, que com José Estêvão lançaram os fundamentos deste organismo de beneficência, agruparamse sob a designação de Associação Protectora do Asilo de S. João em época evidentemente anterior a 8 de Julho de 1862, mas que não é possivel precisar". Reimão, O Asilo de $S$. João.

${ }^{39}$ Regulamento interno do Asylo, cap. I, art. ${ }^{\circ} 5 .{ }^{\circ}$.

${ }^{40}$ Regulamento interno do Asylo, cap. II, art. ${ }^{\circ} .^{\circ}$.
} 
Esta política de policiamento e de fiscalização incluía castigos para os casos infratores. Esses castigos consistiam, sobretudo, na repreensão, na privação das horas de recreio, isolamento dentro da mesma sala ou em quarto separado, por tempo graduado segundo a gravidade da culpa ou falta. Era expressamente proibida a aplicação de castigos corporais. ${ }^{41}$

0 facto de se tratar de raparigas obrigava a um esforço adicional por parte de quem dirigia o dia-a-dia do Asilo. Daí que integrassem a instituição quatro "senhoras inspetoras às quais compete 0 exame minucioso e íntimo do que diz respeito às alumnas" ${ }^{42}$ Naturalmente que se percebe que o elemento feminino estava em maior número no interior do Asilo e em posições-chave: o quadro de pessoal interno era composto por uma regente, uma mestra, uma criada e um criado. A regente era a autoridade interna superior. Competia-Ihe, entre outras obrigações, "vigiar cuidadosamente no aceio e arranjo das alumnas, tratando-as como se fossem suas próprias filhas, e admoestando-as com brandura e afeição". ${ }^{43}$

A aula era dirigida por uma mestra, que podia ser interna ou externa, e tinha por competência lançar diariamente no livro para tal destinado os valores ou notas qualificativas das lições e dos trabalhos executados pelas alunas ${ }^{44}$. As jovens seriam examinadas de três em três meses pela mestra e pela direção, verificando-se por essa ocasião a regularidade do ensino e a aplicação individual de cada formanda. ${ }^{45}$

Em termos escolares, as asiladas tinham um plano curricular que incluía o que estava previsto na lei, para além de saberes que eram exclusivamente dedicados a um público escolar feminino, no caso o adestramento em costura, ou seja, lavores. Essa instrução passava pelo ler, escrever e contar; princípios gerais de moral; doutrina cristã e civilidade; exercícios gramaticais; e princípios de corografia e história portuguesa. ${ }^{46}$

Para além de acolher jovens em regime de internato, o Asilo abriria a suas portas a raparigas que 0 frequentavam, mas em regime externo. $E$ a verdade é que a educação daquelas que, mais tarde, se tornariam mulheres foi uma das pedras angulares do Asilo. Neste sentido, houve aquilo que designaríamos de uma assistência educativa, isto é, a educação no seu sentido escolar integrava cuidados com a higiene e com a saúde das alunas. Era à luz da ideia de civilidade ${ }^{47}$ que 0 tratamento do corpo e do espírito que ali se adestrava.

\footnotetext{
${ }^{41}$ Regulamento interno do Asylo, cap. XI, art. ${ }^{\circ} 35 .{ }^{\circ}$.

${ }^{42}$ Regulamento interno do Asylo, cap. II, art. ${ }^{\circ} 8 .^{\circ}$.

${ }^{43}$ Regulamento interno do Asylo, cap. III, art. ${ }^{0} 10{ }^{\circ}$.

${ }^{44}$ Regulamento interno do Asylo, cap. IX.

${ }^{45}$ Regulamento interno do Asylo, cap. XVI, art. ${ }^{0} 51 .{ }^{\circ}$.

46 "Reforma da Instrução Pública" [decreto de 20 de setembro de 1844], em Reformas e bases da educação - legado e renovação (1835-2009), dirigido por David Justino (Lisboa: Conselho Nacional de Educação, 2017), 73-106.

47 "A civilidade, considerada, na segunda metade de oitocentos, componente fundamental do currículo escolar, surge como uma presença importante, tendo em vista a promoção de uma rede de relações sociais sob 0 signo da harmonia e da polidez e a dissuasão de comportamentos menos adequados", Joaquim Pintassilgo, "A
} 
A frágil condição social feminina, que (sobre)vivia numa sociedade patriarcal, teria uma particular atenção ao longo do século XIX. Ernesto Martins chamaria a atenção para uma das características mais evidentes do discurso educativo deste século, mas que conheceria desenvolvimentos no século seguinte:

[...] uma nova racionalidade sustentada por um discurso predominantemente masculino que produziu a figura de cuidador e protetor no feminino. Esta imagem provém da referência à família e centrada na figura da mãe, guardiã do lar e educadora, de modo que a feminização do setor da proteção da criança inscreveu-se na lógica do movimento maternalista que se impos aos burgueses e à classe trabalhadora, com as mulheres devotadas aos cuidados domésticos e à infância. ${ }^{48}$

No preâmbulo do texto que apresentou 0 ano económico de 1868/1869 da instituição, foi feita uma associação direta entre 0 valor da educação e a assistência à infância desvalida: "É elevada a missão de que o povo português se incumbiu, tomando a seu cargo 0 sustento e educação de um grande número de crianças desvalidas, tornando-as por este modo uteis esteios da árvore abençoada da civilização". ${ }^{49}$

A direção do Asilo sabia bem das dificuldades por que iria passar na condução de uma instituição que incorporava a assistência e a educação, sobretudo porque acolhia apenas jovens do sexo feminino e órfãs. Não era apenas o facto de, pela fortuna da vida, terem ficado sem pai ou mãe, ou ambos os progenitores; a vida que conheceriam num asilo era diferente daquela que teriam no seio familiar mais restrito, "donde resultam inconvenientes que a prática vai demonstrando difíceis de remediar, e as administrações dos asilos vêem-se em dificuldades graves para darem destino às asiladas que completam 0 seu tirocínio". ${ }^{50}$

Nem sempre as fontes são claras no que toca a este ponto do sucesso formativo do asilo. No exercício de 1868/1869, o mapa das alunas externas mostra as dificuldades que 0 asilo tinha em conseguir que obtivessem os resultados esperados: das 22 alunas internas, oito deixaram de frequentar 0 asilo e apenas uma apresentava bastante adiantamento no estudo e costura. As restantes ou apresentavam princípios de adiantamento ou mesmo pouco. Importa dizer que apenas uma das alunas tinha dez anos, e era a mais velha, e havia mesmo crianças com apenas quatro anos. Já no mapa das internas, é possível ver que das 20 , nove obtiveram prémios de mérito e outras duas receberam ofertas (um dedal de prata e um pequeno missal). As alunas mais velhas, com 16 e 15 anos de idade, que foram premiadas, fizeram o exame de admissão ao liceu e foram aprovadas com 14 e 13 valores. ${ }^{51}$

\footnotetext{
"educação doméstica" nos asilos femininos. 0 exemplo do asilo D. Pedro v de Lisboa na transição do século XIX para o século XX", História \& Perspectiva, 38 (2008): 13.

${ }^{48}$ Martins, As infâncias na história social da educação, 177.

${ }^{49}$ Associação Protectora do Asylo de S. João para a infância desvalida. Relatório e contas [anos económicos de 1867/1868 a 1888/1889] (Lisboa: Imprensa Nacional, s.d), 1867-1868, 3.

${ }^{50}$ Associação Protectora do Asylo de S. João, 1867-1868, 4.

${ }^{51}$ Associação Protectora do Asylo de S. João, 1868-1869, 11.
} 
Os elevados custos levaram a direção, nesse ano económico, a pensar num regime de semi-internato para todas as suas alunas. 0 semi-internato era, provavelmente "0 melhor sistema orgânico desta ordem de estabelecimentos, porque, para além de ser mais económico, facilitando portanto a educação a maior quantidade de crianças, tem a vantagem de lhes conservar a família, que no futuro as há de dirigir e aconselhar" ${ }^{52}$

Naturalmente que o regime de internato tinha a vantagem de proteger as jovens asiladas do mundo exterior. Era mais fácil acompanhar 0 crescimento e a formação das alunas que habitavam o edifício do Asilo do que daquelas que, todos os dias, retornavam às suas famílias. A educação das primeiras era da inteira responsabilidade do Asilo e isso era uma vantagem. Mais do que isso: era uma marca distintiva e identificadora do papel social que uma instituição asilar patenteava.

Este orgulho na missão educadora, podemo-lo ler numa espécie de olhar retrospetivo do que fora a ação do Asilo nos primeiros anos de atividade. Entre 1862 e 1874, a instituição tinha acolhido 70 crianças desvalidas, lamentando-se a morte de duas alunas "em resultado do deteriorado e precário estado físico em que foram admitidas". ${ }^{33} 0$ balanço da influência que a instituição tivera na vida das jovens inspirava a dar continuidade a esta obra educadora e assistencial:

[...] não consta que nenhuma destas crianças, de há muito mulheres, se tenha transviado da senda honesta em que e para que foram educadas; e se muito têm concorrido para tal as circunstâncias em que, felizmente, se têm achado depois da saída do asilo, com verdade não se poderá deixar de acreditar que, também em boa e grande parte, a educação que receberam no asilo concorreu para isso. ${ }^{54}$

Apesar das dificuldades, este balanço estava mais próximo, quer nos números quer nos resultados últimos, da vantagem em manter as alunas num regime de clausura. Esta dúvida sobre a melhor maneira de educar jovens não foi exclusiva do ASJ. Com efeito, de acordo com Maria João Mogarro ${ }^{55}$, houve uma acesa discussão em torno do regime de internato em instituições educativas, mesmo no arranque das Escolas Normais. Apesar disso, este regime manteve-se durante, sensivelmente, duas décadas, tendo sido abolido em 1883 na Escola Normal Primária de Lisboa para o sexo feminino.

As saídas profissionais à disposição de jovens asiladas concentravam-se, sobretudo, na via de ensino. Nos anos finais da década de Setenta, a possibilidade da introdução do ensino profissional surgiria no seio do Asilo e só não tinha, até então, avançado de modo efetivo "por culpa do "acanhamento das proporções da casa em que labora 0 asilo, e a circunstância de não se acharem preparadas ad hoc as nossas asiladas". ${ }^{6}$

\footnotetext{
${ }^{52}$ Associação Protectora do Asylo de S. João, 1868-1869, 4.

${ }^{53}$ Associação Protectora do Asylo de S. João, 1873-1874, 5.

${ }^{54}$ Associação Protectora do Asylo de S. João, 1873-1874, 5.

${ }_{55}$ Maria João Mogarro, "A Escola Normal de Lisboa e a formação de professores: percursos, identidade e afirmação sob o signo da pedagogia republicana da educação nova", em 0 edifício da Escola Superior de Educação de Lisboa: 100 anos a formar professores (1916-2016). Ciclo de conferências, coordenado por Nuno Martins Ferreira et al. (Lisboa: Escola Superior de Educação - Instituto Politécnico de Lisboa, 2018), 37-76.

${ }^{56}$ Associação Protectora do Asylo de S. João, 1878-1879, 5.
} 
Em 1878, a Assembleia Geral apreciou a segunda parte ${ }^{57}$ de um relatório elaborado pela direçãa $0^{58}$, no qual se incluíram considerações relativas ao ensino no Asilo e possíveis alterações desta natureza nos estatutos. 0 relatório é um autêntico programa de intenções, apoiadas na importância da concretização do ensino profissional. 0s argumentos partiam de dois pressupostos. 0 primeiro deles era 0 de que, à época, já não era suficiente 0 magistério do ensino primário às jovens asiladas. 0 Asilo assumia a responsabilidade de oferecer uma formação que fosse além do ler, escrever e contar, dada noutros asilos e escolas portuguesas. 0 segundo baseava-se na condição feminina, desde há muito menorizada em relação à masculina:

\begin{abstract}
A preferência que mereceram as crianças do sexo feminino condiz com o espírito liberal, caridoso e esclarecido dos sócios fundadores. Por uma das numerosas incoerências que obliteram o espírito do homem, metade da humanidade tem vegetado numa inferioridade de condições sociais humilhante, odiosa e nociva para si mesma e para a outra metade. ${ }^{59}$
\end{abstract}

Cabendo ao Asilo proporcionar melhores condições de formação e de preparação para a vida profissional daquelas futuras mulheres, os autores do relatório fizeram como que uma autocrítica à forma como a Instituição não se estava a modernizar do ponto de vista educativo. Este texto é verdadeiramente progressista no que concerne à condição da mulher e à expetativa de que este conjunto de homens tinha em relação ao contributo social e económico que as alunas podiam ter no futuro para lá das paredes do Asilo: “[...] parecemos empenhados em rebaixar constantemente esta nossa igual, dando-lhe a educação mais absurda, uma instrução que a deixa ignorante, piegas e inútil, e excluindo-a obstinadamente do exercício de várias funções do comércio, da indústria, das artes e das ciências para que ela seria eminentemente própria" ${ }^{60}$

0 tempo era, portanto, de dar às asiladas, para além da assistência e de uma formação moral, uma instrução de cariz prática, diríamos nós hoje profissionalizante. Muitas das asiladas saíam de uma vida difícil, mas entravam noutra, porque as competências adquiridas ao longo da sua formação não passavam do ler, escrever, contar, coser e bordar. Tal limitava a sua entrada no mundo profissional a servirem como criadas, ou a serem bordadoras e costureiras.

A proposta plasmada neste relatório diversificou as possibilidades de uma formação profissional que, para além das profissões referidas, incluía ensinamentos de contabilidade (caixeiras); composição de tipografia; telegrafia; ginástica e canto coral para ensinarem os alunos no caso de serem professoras. Ao seguir estas diretrizes, o Asilo estava a prestar um serviço de qualidade ao Estado e ao País:

\footnotetext{
${ }^{57}$ Esta segunda parte está incluída no conjunto de relatórios e contas do ASJ. Não se conseguiu, ainda, localizar a parte inicial deste relatório.

${ }^{58}$ Tem as seguintes assinaturas: Jaime Larcher, António José Freixão Coelho, E. Amourous, Francisco dos Santos, Luís Filipe Leite, Vitoriano Estrela Braga, Eduardo Augusto Craveiro.

${ }^{59}$ Asylo de S. João. 2. ${ }^{a}$ parte do relatório da direcção contendo algumas considerações sobre o ensino, $e$ alterações que devem ser introduzidas nos estatutos (1878), 1.

${ }^{60}$ Asylo de S. João. 2. ${ }^{a}$ parte do relatório, 1-2.
} 
"Presenteie-se, em suma, a sociedade portuguesa com mulheres robustas, de moral sã, de inteligência desenvolvida, de instrução prática, verdadeiramente prestantes e de trato agradável. Continuem os diplomas do asilo a ser certidões autênticas de bons costumes". ${ }^{61}$

\section{Notas sobre quotidiano do Asilo}

É através dos relatórios e contas da APASJ que podemos captar alguma da dinâmica do quotidiano da instituição. Como fizemos referência, estes textos não incluem apenas exercícios contabilísticos, apresentando muitas informações sobre a vida da instituição, relativas ao ano económico respetivo.

Da leitura dos vários relatórios e contas da instituição ressaltam as dificuldades por que passaram as direções que geriram 0 Asilo. ${ }^{62}$ São muitas as anotações de carência financeira para mantê-lo em funcionamento, o que obrigaria à abertura a doações feitas por particulares e por associações de beneficência, também elas maçónicas.

No ano económico de 1867/1868, com base nas despesas necessárias ao normal funcionamento, 0 ambiente era de crença no sucesso deste projeto:

Provida de recursos suficientes, a nossa associação cumprirá mais desassombradamente todos os encargos a que está obrigada [...] e poderá melhorar, até alargar, a área dos benefícios que se propôs distribuir sem ostentação, mas proficuamente, aos verdadeiros deserdados da fortuna. A instrução e educação que ministramos, sendo já excelentes graças ao zelo dos ilustres diretores, aos cuidados da solícita regente, e à perícia dos dignos precetores, são, todavia, suscetíveis de se aperfeiçoarem, podem atingir o grau de adiantamento hoje tão reclamado pela civilização ${ }^{63}$

Em 1869, o Asilo albergava 20 jovens, internas, a que se somavam 22 alunas externas. Perante este número expressivo de jovens apoiadas, ainda que as externas fossem mais baratas em termos de custos individuais, a Direção solicitaria vários benefícios, quer a instituições quer a particulares, como consta do mapa de contas deste ano económico. Por exemplo: "Em 13 de janeiro do corrente ano foi este asilo contemplado com a quinta parte do produto de uma receita que 0 distinto ator italiano Ernesto Rossi ${ }^{64} \mathrm{deu}$ a benefício de alguns asilos desta capital, resultando daí a quantia de $45 \$ 573$ réis" ${ }^{\circ}$; e

\footnotetext{
${ }^{61}$ Asylo de S. João. 2. a parte do relatório, 5.

62 O ASJ não foi caso único, dada a incapacidade de autonomia deste tipo de estabelecimento: "Os objetivos de apoio social de beneficência e solidariedade mantinham-se por legados, testamentos, heranças ou subsídios de particulares filantropos e beneméritos, custeando uma ou mais escolas. De facto, as escolas criadas, através de doação e heranças, passaram dificuldades económicas, segundo os rendimentos distribuídos, chegando a abranger outras dádivas (casas, terrenos, quintas, mobiliários), para se manterem ativas durante algum tempo", Martins, As infâncias na história social da educação, 193-194.

${ }^{63}$ Associação Protectora do Asylo de S. João, 1867-1868, 15.

${ }^{64}$ Ernesto Rossi protagonizou Hamlet, de Shakespeare, no Teatro do Príncipe Real, em 1868, tendo regressado diversas vezes a Portugal.

${ }^{65}$ Associação Protectora do Asylo de S. João, 1868-1869, 5.
} 
"do ilustríssimo senhor Henrique Freire, 11 livros intitulados 0 rei e o soldado para uso nas aulas do asilo". 66

As ofertas de livros ao Asilo foram uma constante, pelo menos durante os seus primeiros vinte anos. 0 exercício de 1869/1870 dava conta das seguintes doações: dez exemplares dos Estudos biográficos dos principaes pintores, oferecidos por Maria do Carmo Feijó de Sousa; e quatro exemplares dos Elementos de Pedagogia e seis da Chorographia de Portugal, por Henrique Lima Freire. Em 1873/1874, João Eusébio de Oliveira e 0 Cónego Vivas, de Faro, doaram bastantes livros para leitura na aula. ${ }^{67}$

A angariação de fundos feita pela APASJ no ano económico de 1870/1871 permitiria obras nas instalações do Asilo, urgentes, mas até então adiadas por culpa de receita insuficiente. Mais do que melhoramentos nas estruturas físicas da instituição, o principal objetivo fora 0 de se mudar para instalações com melhores condições de habitabilidade. $\mathrm{Na}$ curta história do Asilo, as alunas tinham estado sediadas numa casa na Rua dos Navegantes, n. ${ }^{\circ} 62$ (Lapa), mais precisamente no Palácio Sarmento e, depois, na Rua da Barroca (Bairro Alto). A primeira tinha sido desocupada para ser arrendada pelo proprietário, na segunda metade de 1865, e a segunda não dispunha de condições de acomodação interna e higiénicas.

0 Asilo transitaria, em 1871, para uma nova casa, na Travessa do Loureiro, n. ${ }^{0}$ 10, arruamento no qual ainda permanece nos dias de hoje. À época, a renda era superior à que pagavam no Palácio Sarmento, mas "não duvidou a direção alugá-la, não só porque se prestava a melhor acomodação do asilo, como pelas condições higiénicas resultantes do local, e da sua forma desafrontada de habitações particulares, tendo as frentes sobre grandes espaços". ${ }^{68}$

A nova casa dispunha de jardim e de um amplo pátio de entrada ${ }^{69} \mathrm{~A}$ mudança era benéfica, em termos de espaço, de segurança de adultos, crianças e adolescentes, mas igualmente em termos de contacto com a vizinhança:

[...] boa ventilação e insolação, isto é, ar puro e luz, condições essenciais à vida, principalmente para a idade das asiladas; e espaço para estas poderem andar mesmo sem saírem do asilo, vantagens são, que é inútil demonstrar ou encarecer para mostrar quanto as asiladas ganharam com a mudança, não falando de alguma vizinhança, que as cercava na rua da Barroca, cujos péssimos exemplos de

\footnotetext{
${ }^{66}$ Associação Protectora do Asylo de S. João, 1867-1868, 7. Trata-se do livro 0 rei e o soldado: facto histórico do reinado do senhor dom Pedro (Setúbal: José Augusto Rocha, 1862).

${ }^{67}$ Associação Protectora do Asylo de S. João, 1873-1874, 7.

${ }^{68}$ Associação Protectora do Asylo de S. João, 1870-1871, 20.

${ }^{69}$ Esta busca por um espaço que permitisse às asiladas 0 contacto com 0 ar livre podemos encontrá-la na instalação do Asilo de São João do Porto, cuja primeira residência, na Rua da Alegria, arrumamento de onde já não sairia, possuía uma casa com jardim e quintal. Este local fora "referenciado [...] como um dos mais saudáveis da cidade, adequado para 0 bem-estar das crianças que [...] chegavam em geral anémicas e atrofiadas, pela escassez de recursos das pessoas que delas cuidavam", Santos, "0 Asilo de S. João do Porto", 93.
} 
vida, de costumes e de linguagem, em flagrantíssima e continuada contradição com as ideias de sã moral e de educação, que recebem no asilo as asiladas, funestamente podiam influir no seu futuro. ${ }^{70}$

Também diferentes associações fizeram doações, em géneros ou em dinheiro: por exemplo, no ano económico de 1873/1874, a Sociedade, Pátria e Família, do Porto, doou cinco exemplares dos Lusíadas para prémios a atribuir às melhores alunas. ${ }^{71} \mathrm{~A}$ associação filantrópica Cosmopolite entregou duas dotações de $20 \$ 000$ réis cada uma, e 0 conselheiro João Gualberto de Barros e Cunha, à época ministro e secretário de Estado das Obras públicas, Comércio e Indústria, "destinou a dotação de $50 \$ 000$ réis, para as três crianças que mais distintas fossem pelo seu aproveitamento"72. Em 1871/1872, encontramos a informação de que 0 Grande Oriente Lusitano Unido contribuiu com $78 \$ 000$ e a Sociedade Tolerância com $4 \$ 200$.

Com o passar dos anos, as dificuldades em gerir o dinheiro eram evidentes e a solução passava por atos de filantropia. Uma das causas para a abertura ao auxílio dado por associações filantrópicas estava na continuidade em assegurar formação a alunas externas. Desde 1873, que a direção do Asilo mantinha cabimento para a atribuição de um vestuário completo a cada uma das jovens externas, cujo número ascendia a 46! 0 relatório dava conta de uma despesa total de "130\$020 réis, caridosamente dados por aquelas associações, que são: Oriente Lusitano, Pureza e Regeneração Irlandeza". ${ }^{73} \mathrm{Em}$ 1874, a cada uma das alunas externas seria distribuído no dia de São João um vestuário completo, fazendo jus aos donativos publicitados. ${ }^{74}$

0 exercício de 1880/1881 apresentou um resumo do estado em que se encontrava 0 Asilo e quais eram os seus principais problemas. 0 custo diário de cada asilada, no que ao ensino dizia respeito, cifrava-se na quantia de $039 \$ 26$, quantia que incluía aulas e ordenados da professora e da regente. Para os seus responsáveis, esta quantia era manifestamente insuficiente para fazer face às despesas a que estavam obrigados:

\begin{abstract}
Não basta. É sem dúvida excelente abrigar, sustentar e vestir durante anos consecutivos as pobres crianças de que tomámos conta, bem como tratar-Ihes da saúde e robustecer a daquelas (quase todas), que nos chegam linfáticas, escrofulosas e anémicas, e corrigir-lhes os vícios provenientes da família e da miséria. Excelente é também cuidar-Ihes da educação moral, e neste ponto pode 0 asilo de S. João disputar a palma a qualquer dos seus congéneres. Mas é forçoso confessar que o subsídio oferecido à instrução é mesquinho, e que a missão que nos incumbe olha tanto para a mulher robusta, sadia e moral, como para a mulher instruída e prestadia para si e para a sociedade. A instrução é capital com que dotamos as asiladas, é garantia que lhes damos da subsistência bastante e honesta, é um serviço prestado à sociedade em geral. ${ }^{75}$
\end{abstract}

\footnotetext{
${ }^{70}$ Associação Protectora do Asylo de S. João, 1870-1871, 20.

${ }^{71}$ Associação Protectora do Asylo de S. João, 1870-1871, 5

${ }^{72}$ Associação Protectora do Asylo de S. João, 1873-1874, p. 5.

${ }^{73}$ Associação Protectora do Asylo de S. João, 1873-1874, 5.

${ }^{74}$ Associação Protectora do Asylo de S. João, 1874-1875, 31.

${ }^{75}$ Associação Protectora do Asylo de S. João, 1880-1881, 5.
} 
0 Asilo proporcionou, também, momentos de lazer aliados a questões de higiene. $\mathrm{Na}$ segunda metade do século XIX emergiu no discurso médico-pedagógico a importância da criação de condições higiénicas, que viriam a caracterizar a prática educativa. Essas condições incluíam banhos, instalações sanitárias ou refeições ${ }^{76}$. De um lado desta nova conceção de educação, estava a higiene e do outro a prática da educação física, ambas "uma representação simbólica da vontade de transformar simultaneamente 0 corpo e a alma das futuras educadoras do povo, que criariam o homem novo, 0 novo cidadão". ${ }^{77}$

Nas fontes, encontramos várias referências às condições higiénicas e sanitárias, vitais para a criação de um ambiente educativo sem problemas de saúde. Em 1872/1873, a monitorização da salubridade das instalações dava conta da proteção garantida aos funcionários e alunas, num contexto de doença generalizada: a cidade de Lisboa tinha conhecido crises epidémicas de cólera e febre-amarela, nos anos de 1856 e 1857, calculando-se em cerca de 6000 o número de vítimas mortais ${ }^{78 ;}$ nos anos de 1867 e 1868, a capital tinha sido assolada, mais uma vez, por uma crise de mortalidade provocada pelo alastramento de febres tifoides, tifo e gripes, e entre 1872 e 1879 "o tifo exantemático voltou a ser uma das causas prováveis da sobremortalidade da população"79.

De acordo com o relatório e contas de 1872/1873, o estado sanitário do Asilo não inspirava cuidados de maior, não se tendo manifestado

\begin{abstract}
felizmente caso algum das epidemias que com tão grande intensidade e persistência houve na cidade, principalmente nas crianças; a verba despendida em medicamentos foi pois insignificante se se considerar o número de crianças recolhidas no asilo, e a que avulta com a compra de óleo de fígado de bacalhau para combater e atenuar os efeitos da complexão linfática que apresentam a maior parte das crianças no ato de admissão, e que é natural consequência das circunstâncias precárias em que viviam. ${ }^{80}$
\end{abstract}

Era habitual levar as alunas a atividades ao ar livre, de modo a zelar pela sua condição física. A proximidade com o rio e o mar levou a direção do Asilo a organizar saídas, mais ou menos prolongadas, pois "os banhos de mar são um poderoso corretivo das constituições definhadas e um auxílio eficaz do desenvolvimento das crianças" ${ }^{81}$. As asiladas eram transportadas do cais do Aterro da Boa Vista para a margem sul do Tejo, para

\footnotetext{
${ }^{76} 0$ caso do Asilo de São João do Porto é ilustrativo da preocupação em oferecer aos educandos práticas pedagógicas diversificadas e condições higiénicas que, no final do século XIX, não constituíam a regra entre os estabelecimentos de internato educativo. Santos, "0 Asilo de S. João do Porto".

77 Mogarro, "A Escola Normal de Lisboa", 42.

78 Joana Cunha Leal, "A sanitarização do imaginário urbano e o crescimento de Lisboa na segunda metade do século XIX», em Arte \& Poder, editado por Margarida Acciaiuoli, Joana Cunha Leal e M. Helena Maia (Lisboa: IHA / Estudos de Arte Contemporânea, 2008), 119-135.

${ }^{79}$ Maria Hermínia Barbosa, Crises de Mortalidade em Portugal desde meados do século XVI até ao início do século XX (Guimarães: Núcleo de Estudos de População e Sociedade - Instituto de Ciências Sociais da Universidade do Minho, 2001), 34.

${ }^{80}$ Associação Protectora do Asylo de S. João, 1872-1873, 22.

${ }^{81}$ Associação Protectora do Asylo de S. João, 1878-1879, 4.
} 
a ida a banhos nos meses de verão. De modo a evitar o cansaço de viagens diárias de ida e volta, a direção do Asilo resolveria arrendar uma casa na Cova da Piedade

para onde foi todo o pessoal do asilo durante mês e meio, ali encontrou 0 asilo mais um benévolo protetor, [...] Pompeu Dias Torres, que deu combustível, emprestou mobília, e facilitou quanto possível a questão dos banhos [...] as crianças, tomando comodamente os seus banhos, em águas limpas, correndo alegres à sombra dos pinheiros, cujas emanações balsâmicas respiravam, alimentando-se em proporção do seu apetite [...]. ${ }^{82}$

No ano seguinte, as asiladas seguiriam para o Barreiro, que por lá ficariam durante 0 período da estação balnear: "[...] ali estiveram as crianças durante dois meses, incessantemente vigiadas pelo nosso colega Francisco dos Santos, que para ali fôra morar com sua família". 83

No início do século XX começou a ser construído um edifício na linha de Cascais, mais precisamente na Parede, num terreno que havia sido doado pelo benemérito José Nunes da Mata, para que as jovens alunas pudessem passar “n'essa bela estação balnear uma parte do verão e tomar os seus banhos, do que Ihes resultará um grande benefício para a sua saúde" ${ }^{84}$ Apesar das doações de dinheiro recebidas, a sua construção sofreu atrasos, porque a direção do Asilo não tinha saldo disponível para finalizar o edifício. A obra arrancaria em 1905, mas no ano seguinte e até 1908 a construção pararia. Em 1909, a 26 de novembro, comemorou-se 0 centenário do nascimento de José Estêvão, efeméride a que o Asilo se associaria, por se tratar do seu fundador. Numa carta aberta, subscrita pelos membros dirigentes da instituição e datada de 12 de maio desse ano, pediram-se apoios para a realização de uma quermesse no dia de São João, que permitisse angariar verbas para a finalização daquele edifício. 0 principal objetivo era o de inaugurar, precisamente no dia da comemoração dos cem anos do nascimento do ilustre fundador, aquele novo sanatório balnear. Apenas em setembro de 1910, o edifício ficaria preparado para ser habitado. ${ }^{85}$

\section{Conclusão}

0 Asilo viria a conhecer modificações regulamentares e alterações no seu modus operandi, sobretudo com o fim da Monarquia e a eclosão da nova ordem republicana. Sabe-se que o plano formativo seria ampliado com a reforma dos seus Estatutos em 1914, de forma a permitir um ensino profissional, passando a incluir 0 ensino de contabilidade,

\footnotetext{
${ }^{82}$ Associação Protectora do Asylo de S. João, 1878-1879, 4.

${ }^{83}$ Associação Protectora do Asylo de S. João, 1879-1880, 5. Os educandos do Asilo de São João do Porto só puderam usufruir de colónias de férias organizadas no tempo do Estado Novo. Como tal, manteve-se um sistema de viagens diárias à praia durante quinze dias no verão, apoiadas pela Companhia Carris de Ferro. Santos, "0 Asilo de S. João do Porto".

${ }^{84}$ Carta da direção do Asilo de São João pedindo apoios para uma quermesse, Fundação Mário Soares / FBM

- Fundo Bernardino Machado, 1909.

${ }^{85}$ Azevedo, História do Internato de S. João de Lisboa.
} 
noções de escrituração comercial, datilografia, caligrafia, lavores artísticos, arte aplicada, corte de roupa branca, desenho, culinária, enfermagem e música.

Apesar das dificuldades inerentes à vida de uma instituição desta natureza, de iniciativa privada e carente da atenção e apoio de particulares e de coletividades, o número de asiladas chegou a atingir 80, tendo-Ihes 0 asilo proporcionado, até à idade de 18 anos, alimentação, vestuário, educação laica, incluindo instrução literária, trabalhos manuais e ensino profissional.

No final da década de Vinte do Século XX, seriam criados diversos cursos profissionais, para além da manutenção da instrução geral. As jovens com 0 exame da 4 . $^{\text {a }}$ classe estudavam por mais 3 anos podendo fazer depois as disciplinas de português, francês, história-pátria e noções de geografia geral, noções de ciências físico-naturais, aritmética, contabilidade e noções de escrituração comercial elementar, datilografia, caligrafia, lavores artísticos, arte aplicada e corte de roupa branca, desenho, ginástica, culinária, corte e confeção de vestidos e de chapéus, enfermagem rudimentar, música e canto coral. As visitas de estudo e as férias de verão com banhos de mar na praia da Parede foram uma extensão importante da formação de jovens raparigas. ${ }^{86}$

A estreita ligação entre a ação de maçons e o surgimento do Asilo levanta uma questão investigativa que carecerá de um maior aprofundamento. Referimo-nos à ação no campo educativo que as obediências maçónicas tiveram no decorrer do século XIX e nas primeiras décadas do do século XX. Muitos daqueles que compuseram lojas maçónicas foram personalidades com trajetórias intelectuais respeitadas pelos seus contemporâneos. Ora, há uma evidente lacuna historiográfica no que toca ao facto de terem sido maçons com intervenção social e cultural, nomeadamente na instrução e educação de crianças, jovens e adultos. Até do ponto de vista da história das maçonarias portuguesas, há um campo investigativo por explorar quanto ao modo como os seus membros construíram redes de distribuição e de apropriação de capital cultural. ${ }^{87}$

No caso do ASJ, mas também no do Porto ${ }^{88}$, não há evidências, para os primeiros anos do seu funcionamento, de qualquer projeto educativo ou pedagógico que enquadrasse a missão da Instituição. Ao contrário do Asilo do Porto, que conheceu

\footnotetext{
${ }^{86}$ Maria Rosa Tomé, “Cidadania Infantil em Portugal (1820-1978). A Tutoria de Coimbra” (Tese de Doutoramento, Universidade de Coimbra, 2012).

${ }^{87}$ Giana Amaral chamou precisamente a atenção para esta pista investigativa ao estudar a Maçonaria brasileira, mas que se aplica igualmente ao caso português. Giana Lange do Amaral, "Os maçons e a modernização educativa no Brasil no período de implantação e consolidação da República", História da Educação, 21(53) (2017): 56-71.

${ }^{88}$ Como apontou Santos, Memórias do Internato de S. João do Porto, 41, as grandes motivações para a criação daquela Asilo fundaram-se na prática da beneficência e da solidariedade, "não havendo, por isso, lugar para a explanação prévia de quaisquer teorias pedagógicas ou outras, a não ser o desejo expresso de ministrar aos menores desvalidos, que queriam proteger, uma educação física, moral e intelectual que os preparasse para as luctas da vida [...]".
} 
um tempo de preparação antes de entrar em funcionamento, ${ }^{89} 0$ contexto em que foi criado o ASJ, num curto espaço de tempo e como resposta ao vazio deixado pelas Irmãs da Caridade, não permitiu a maturação de um projeto daquela natureza. Contudo, há que conhecer melhor as influências pedagógicas assumidas pelas direções do ASJ e averiguar a existência, ou não, de ligações com outros estabelecimentos nacionais e estrangeiros.

Sabemos os nomes daqueles que compuseram a comissão proponente da criação do Asilo ou daqueles que fizeram parte da sua primeira direção. Não é difícil traçar uma linha biográfica com os principais aspetos das suas vidas pessoais e profissionais, mas interessará mais conhecer os seus trajetos prosopográficos intelectuais e sociais, a partir do papel que desempenharam na qualidade de maçons ou na perspetiva da influência que a pertença à Maçonaria provocou nas suas relações com a sociedade.

Por último, a história das instituições asilares revela-se como uma oportunidade de investigação importante. ${ }^{90} 0$ modo como se estabeleceram; as idiossincrasias próprias deste tipo de instituições mais próximas de faixas populacionais débeis e desprotegidas; ou a sua obra social e assistencial de matriz liberal, que ia mais além da dimensão educativa, são pontos que devem merecer a atenção da historiografia. ${ }^{91}$ Que trajetos tomaram as jovens que se formaram no ASJ? Que visibilidade social conheceram, depois da sua passagem pela instituição ${ }^{92}$ Serão outras questões que ajudarão a desvendar o papel que a figura institucional do Asilo, depois Internato, teve na sociedade portuguesa. $^{93}$

\footnotetext{
${ }^{89}$ Santos, Memórias do Internato de $S$. João do Porto, refere a experiência adquirida pela Maçonaria na criação e projeção de estabelecimentos deste género, dando o exemplo do ASJ e do Asilo-Escola António Feliciano Castilho para crianças de ambos os sexos, criado em Lisboa, em 1889. Por outro lado, decorreriam dois anos entre a primeira reunião da sua Comissão Fundadora e 0 arranque da atividade do Asilo.

${ }^{90}$ Já em 2000, um importante artigo de Rogério Fernandes apontava lacunas investigativas que, ainda hoje, são visíveis: "0 movimento das Casas de Asilo em Portugal, apesar de inspirado visivelmente pela inovação francesa, inscreve-se num conjunto de contextualizações determinantes (políticas, econômicas, sociais, médicas, demográficas, culturais), de que não temos ainda uma visão geral." Rogério Fernandes, "Orientações pedagógicas das "casas de asilo da infância desvalida"”, Cadernos de Pesquisa, 109 (2000): 91.

91 "O desafio colocado à História da Educação em se assumir numa área da História, não implica fazer economia das suas transformações teóricas e metodológicas recentes. Há toda uma série de vinculações necessárias, com a história económica e social, com a história política, da cultura, das ciências [...] para poder articular as diferentes esferas da realidade e ao mesmo tempo conhecer as práticas educativas nas instituições (escolares e não escolares)", Martins, As infâncias na história social da educação,149.

${ }^{92} \mathrm{Na}$ investigação feita por Santos, Memórias do Internato de S. João do Porto, é possível acompanhar alguns dos trajetos dos educandos daquela Instituição, alguns deles de sucesso e de reconhecimento pelo papel que aquele Asilo teve nas suas vidas.

${ }^{93}$ Como ponto de partida para a investigação destas questões, sugere-se a leitura de Maria João Mogarro e Silvia Alicia Martínez, "Normalistas e meninas de asilo: Origens sociais e percursos de vida no século XIX em Portugal e no Brasil", Sísifo. Revista de Ciências da Educação, 11 (2010): 45-54.; e os já citados Mogarro, "A Escola Normal de Lisboa" e Pintassilgo, "A "educação doméstica" nos asilos femininos".
} 


\section{Bibliografia}

\section{Fontes}

Associação Protectora do Asylo de S. João para a infância desvalida. Relatório e contas [anos económicos de 1867/1868 a 1888/1889] (Lisboa: Imprensa Nacional, s.d).

Asylo de S. João. 2. ${ }^{a}$ parte do relatório da direcção contendo algumas considerações sobre 0 ensino, e alterações que devem ser introduzidas nos estatutos (s.l., 1878).

Carta da direção do Asilo de São João pedindo apoios para uma quermesse, Fundação Mário Soares / FBM - Fundo Bernardino Machado, 1909.

Castelo-Branco, Camilo. Maria da Fonte (Porto: Livraria Chardron, 1900).

Estêvão, José. Discursos Parlamentares (Aveiro: Câmara Municipal de Aveiro, 1997).

Herculano, Alexandre. Ao Partido Liberal Portuguez, a Associação Popular Promotora da Educação do Sexo Feminino (Lisboa: Imprensa União Typographica, 1858).

Parecer da maioria da comissão especial da Câmara dos Deputados sobre a proposta do Governo acerca das Congregações Religiosas e do ensino, apresentado na sessão de 26 de abril de 1862 (Lisboa: Typographia da Sociedade Typographica Franco-Portugueza, 1862).

"Reforma da Instrução Pública" [decreto de 20 de setembro de 1844]. Em Reformas e bases da educação - legado e renovação (1835-2009), dirigido por David Justino, 73-106. Lisboa: Conselho Nacional de Educação, 2017.

Regulamento Interno do Asylo De S. João approvado e mandado observar pela Associação Protectora do mesmo Asylo, (Lisboa: Typographia Portugueza, 1865).

\section{Estudos}

Amaral, Giana Lange do. "Os maçons e a modernização educativa no Brasil no período de implantação e consolidação da República", História da Educação 21(53) (2017): 56-71.

Azevedo, Manuel Roque de. História do Internato de S. João de Lisboa (ex-Asilo de $S$. João) - 1862-1987. 125 anos de solidariedade social [texto policopiado, 1992].

Barbosa, Maria Hermínia. Crises de Mortalidade em Portugal desde meados do século XVI até ao início do século XX (Guimarães: Núcleo de Estudos de População e Sociedade - Instituto de Ciências Sociais da Universidade do Minho, 2001). 
Carvalho, José. "Anticlericalismo/anticatolicismo e clericalismo/catolicismo em Portugal nas vésperas da I República (1881-1910) - breve panorâmica histórico", Revista Lusófona de Ciência das Religiões 20 (2017): 283-311.

Catroga, Fernando. "As maçonarias liberais e a política." Em História de Portugal [vol. 5], dirigido por José Mattoso, 204-211. Lisboa: Círculo de Leitores, 1993.

Catroga, Fernando. "0 livre-pensamento contra a Igreja. A evolução do anticlericalismo em Portugal (séculos XIX-XX)”, Revista de História das Ideias 22 (2001): 255-354.

Cordeiro, Ricardo. "Filantropia. As Cozinhas Económicas de Lisboa (1893-1911)." Dissertação de Mestrado, ISCTE - Instituto Universitário de Lisboa, 2012.

Costa, Fernando Marques. As mulheres na Maçonaria. Portugal: 1864-1950 (Lisboa: Âncora Editora; Campo da Comunicação, 2016).

Costa, Fernando Marques. A Maçonaria entre a forca e o cacete, entre o mito e a realidade. 1807-1834 (Lisboa: Campo da Comunicação, 2018).

Fernandes, Rogério. "Orientações pedagógicas das "casas de asilo da infância desvalida"”, Cadernos de Pesquisa, 109 (2000): 89-114.

Leal, Joana Cunha. "A sanitarização do imaginário urbano e o crescimento de Lisboa na segunda metade do século XIX." Em Arte \& Poder, editado por Margarida Acciaiuoli, Joana Cunha Leal e M. Helena Maia, 119-135. Lisboa: IHA / Estudos de Arte Contemporânea, 2008.

Lopes, Maria Antónia. Protecção social em Portugal na Idade Moderna. Guia de estudo e de investigação (Coimbra: Imprensa da Universidade de Coimbra, 2010).

Marques A. H. de Oliveira. História da Maçonaria em Portugal. Política e Maçonaria, $1820-$ 1869 (1. ${ }^{a}$ parte) (Lisboa: Editorial Presença, 1996).

Marques A. H. de Oliveira. A Maçonaria em Portugal (Lisboa: Gradiva, 1998).

Marques A. H. de Oliveira. "A conjuntura." Em Portugal e a Regeneração (1851-1900), dirigido por Fernando de Sousa e A. H. de Oliveira Marques [Nova História de Portugal, vol. X], 467-518. Lisboa: Editorial Presença, 2004.

Martins, Ernesto Candeias. As infâncias na história social da educação. Fronteiras e interceções sócio-históricas (Lisboa: Editorial Cáritas, 2018).

Mogarro, Maria João. "A Escola Normal de Lisboa e a formação de professores: percursos, identidade e afirmação sob o signo da pedagogia republicana da educação 
nova." Em 0 edifício da Escola Superior de Educação de Lisboa: 100 anos a formar professores (1916-2016). Ciclo de conferências, coordenado por Nuno Martins Ferreira et al., 37-76. Lisboa: Escola Superior de Educação - Instituto Politécnico de Lisboa, 2018.

Neto, Vítor. 0 Estado, a Igreja e a Sociedade em Portugal (1832-1911) (Lisboa: Imprensa Nacional-Casa da Moeda, 1998).

Pintassilgo, Joaquim. "A "educação doméstica" nos asilos femininos. 0 exemplo do asilo D. Pedro v de Lisboa na transição do século XIX para o século XX", História \& Perspectiva 38 (2008): 139-162.

Quaresma, Vítor Sérgio. A Regeneração. Economia e sociedade (Lisboa: Dom Quixote, 1998).

Reimão, Ventura. $O$ Asilo de S. João. Monografia a apresentar ao X Congresso Internacional de Protecção à Infância, Lisboa (Caxias: Tipografia do Reformatório Central de Lisboa Padre António de Oliveira, 1931)

Ribeiro, José Silvestre. Historia dos estabelecimentos scientificos, litterarios e artisticos de Portugal nos successivos reinados da Monarchia (Lisboa: Academia Real das Ciências, 18 tomos, 1871-1914).

Santos, Maria José Moutinho. Memórias do Internato de S. João do Porto (1890-1974) (Porto: Associação Protetora do ISJ, 2012).

Santos, Maria José Moutinho. 0 Asilo de S. João do Porto entre a nova pedagogia e 0 higienismo (1890-1926), CEM - Cultura, Espaço \& Memória, 5 (2014): 89-100.

Tomé, Maria Rosa. "Cidadania Infantil em Portugal (1820-1978). A Tutoria de Coimbra." Tese de Doutoramento, Universidade de Coimbra, 2012.

Ventura, António. Uma história da Maçonaria em Portugal. 1727-1986 (Lisboa: Temas e Debates; Círculo de Leitores, 2020).

Zuber, Valentine. "A laicidade republicana em França ou os paradoxos de um processo histórico de laicização (séculos XVIII-XXI)”, Ler História 59 (2010): 161-180. 